\title{
INTOXICAÇÃO POR MONENSINA EM OVINOS
}

\section{Monensin poisoning in sheep}

SOUZA, T.S.'; COSTA, J.N.'; SILVA, A.E.2; MOREIRA, E.L.T.2; FERREIRA, M.M.'; COSTA, A.F. ${ }^{2}$

${ }_{1}$ Centro de Desenvolvimento da Pecuária - Escola de Medicina Veterinária - UFBA

${ }^{2}$ Laboratório de Anatomia Patológica - HOSPMEV - UFBA

Endereço para correspondência: Thiago Sampaio - thiago_sampaio@hotmail.com

\section{RESUMO}

O objetivo deste trabalho foi descrever um surto de intoxicação por ionóforo em um rebanho de ovinos, onde vinte animais morreram após o uso de monensina sódica na dieta. Os sinais clínicos apresentados pelos animais incluíram hipertermia, anorexia, diarréia, taquicardia, resistência a exercícios e marcha irregular. Na necropsia de um animal, foram constatadas áreas pálidas na musculatura esquelética e no miocárdio, hemorragias no epicárdio e edema pulmonar. O exame histopatológico revelou degeneração e necrose hialina segmentar multifocal das miofibras, que perderam 0 padrão normal de estriação e se apresentaram intensamente eosinofílicas.

Palavras-chave: intoxicação, ionóforo, carneiro.

\section{ABSTRACT}

An outbreak of monensin poisoning in a sheep flock is reported. Twelve animals died after the owner used monensin in the diet. Clinical signs included fever, anorexia, diarrhea, tachycardia, reluctance to move and ataxia. Necropsy findings were observed in one of the sheep that died and consisted of pale areas in the skeletal muscles and myocardium, cardiac hemorrhages and edema of lungs. Histologically, the pale areas in the skeletal muscles and myocardium corresponded to segmental and multi-focal hyaline degeneration and necrosis of myofibers that had lost their normal striation pattern and were deeply eosinophilic.

Key words: poisoning; monensin, ovine.

\section{INTRODUÇÃO}

A monensina é um antibiótico carboxílico poliéter ionóforo sintetizado pelo fungo Streptomyces cinnamonenesis, sendo utilizada na pecuária para maximizar a eficiência produtiva a partir da manipulação da fermentação ruminal, aumentando a formação de ácido propiônico frente ao decréscimo dos ácidos acético e butírico, diminuindo a formação de metano e reduzindo a proteólise e a desaminação da proteína dietética. Inicialmente os ionóforos foram utilizados como coccidiostáticos em aves e atualmente são os aditivos mais pesquisados em dietas de ruminantes (Afonso et al., 2000; Nicodemo, 2001; Oliveira et al., 2005).

Os ionóforos são assim denominados devido a sua capacidade em interagir passivamente com íons formando 
complexos lipossolúveis servindo, desta forma, como veículos de transporte iônico através de membranas biológicas com resultante alteração da homeostase intracelular levando a distúrbios celulares funcionais e morfológicos (Bezerra Jr. et al., 2000; Afonso et al., 2000; Nicodemo, 2001).

A monensina é rapidamente excretada após sua ingestão, com mínimo acúmulo nos tecidos animais. Entretanto, existe a possibilidade de que a taxa de excreção metabólica seja excedida e efeitos tóxicos surjam em animais recebendo dieta com monensina ou em seres humanos consumindo tecidos desses animais. Dessa forma, concentrações elevadas de ionóforos na dieta podem levar à intoxicação. Os tecidos primariamente afetados são o muscular estriado cardíaco e 0 esquelético. A suscetibilidade à intoxicação varia consideravelmente entre as espécies, sendo que os eqüinos são os mais sensíveis. Em ovinos afetados, as concentrações plasmáticas de creatinina fosfoquinase estão elevadas e os sinais clínicos incluem anorexia, diarréia, ataxia, debilidade muscular, perda de peso, recumbência e morte. A maior parte dos problemas de intoxicação dá-se no período inicial de adição de ionóforo à dieta e muitas vezes envolvem erros na mistura e superdosagem (Nicodemo, 2001; Mendes et al., 2003).

Dessa forma, este trabalho teve como objetivo descrever um surto de intoxicação por ionóforo em ovinos após administração de monensina sódica na dieta do rebanho.

\section{MATERIAL E MÉTODOS}

Três ovinos da raça Santa Inês deram entrada na Clínica de Ruminantes do Centro de Desenvolvimento da Pecuária da Escola de Medicina Veterinária da Universidade Federal da Bahia
(CDP/EMV/UFBA), sendo duas ovelhas de aproximadamente um ano e meio de idade e um carneiro morto de cinco anos de idade. Esses animais foram provenientes de uma propriedade rural localizada no município de Cabaceiras do Paraguaçu Bahia, onde 19 ovelhas, entre jovens e adultas, já haviam morrido. O sistema de criação desta propriedade era extensivo, consorciando ovinos e caprinos, sendo que os animais tinham acesso à aguada natural e eram mineralizados, vermifugados e vacinados contra clostridioses.

Seis dias antes do atendimento, o proprietário modificou a dieta do rebanho, fornecendo monensina sódica ad libitum misturada ao sal mineral, não seguindo as recomendações do fabricante, sendo que o produto comercial tinha indicação para uso em bovinos. As duas ovelhas atendidas foram internadas e o cadáver foi submetido à necropsia, sendo que fragmentos de músculo esquelético e miocárdio foram colhidos, acondicionados em formalina a $10 \%$ e enviados para realização de análise histopatológica no Laboratório de Anatomia Patológica do Hospital Veterinário da UFBA.

\section{RESULTADOS E DISCUSSÃO}

De acordo com o proprietário, os primeiros animais vieram a óbito cinco dias após a oferta ad libitum de mistura contendo sal mineral e monensina sódica em proporções não mensuradas. Com isso, optou-se por retirar a mistura dos cochos. Entretanto, no dia seguinte, um carneiro veio a óbito e foi observado que duas ovelhas estavam apresentando os mesmos sintomas clínicos dos animais que já haviam morrido.

Os sinais clínicos apresentados pelos dois animais atendidos na clínica foram apatia, hiperemia das mucosas aparentes, hipertermia, desidratação, anorexia, movimentos ruminais fracos, 
diarréia, taquicardia (freqüência cardíaca média de 120bpm), taquipnéia (freqüência respiratória média de $80 \mathrm{mrm}$ ), resistência a exercícios e marcha irregular. O hemograma apontou monocitose. Achados clínicos semelhantes foram relatados por outros autores em casos de intoxicação por ionóforos em bovinos (Van Vleet et al., 1983; Gava et al., 1997; Gonzales et al., 2005), búfalos (Rozza et al., 2007), ovinos (Nation et al., 1982; Wouters et al., 1997; Mendes et al., 2003) e eqüinos (Bezerra Jr. et al., 2000).

Entretanto, algumas alterações clínicas relatadas em outros casos não foram observadas, como sialorréia (Rozza et al., 2007), urina escura (Gava et al., 1997; Wouters et al., 1997; Mendes et al., 2003), gemidos e ranger de dentes (Wouters et al., 1997; Bezerra Jr. et al., 2000), sudorese (Bezerra Jr. et al., 2000) e apoio da cabeça em objetos (Wouters et al., 1997).

Os sinais clínicos relacionados à musculatura esquelética tais como relutância ao exercício e marcha irregular podem ser resultantes do efeito dos antibióticos ionóforos na distribuição dos íons sódio, potássio e cálcio nas miofibras (Bezerra Jr. et al., 2000).

Em animais intoxicados com antibióticos ionóforos apresentando edema pulmonar associado aos sinais de distúrbios respiratórios, a lesão pulmonar tem sido responsabilizada pela ocorrência de respiração entrecortada, ofegante e taquipnéia. Alternativamente ou concomitantemente é possível que os sinais clínicos sejam devidos à incapacidade funcional dos músculos envolvidos na respiração, associada ou não a alterações morfológicas (Wouters et al., 1997).

Wouters et al. (1997) não associaram o grau de lesão muscular com o aumento da temperatura em ovinos intoxicados por antibióticos ionóforos, ressaltando que provavelmente a hipertermia seja resultado da ação direta da droga ou de um metabólito gerado por ela, agindo como pirogênio exógeno.

A ocorrência da intoxicação somente em alguns animais do rebanho bem como as variações na evolução do quadro clínico devem estar relacionadas às diferentes quantidades ingeridas por animal. $O$ fornecimento do ionóforo em cocho comunitário permitiu que alguns animais ingerissem maior quantidade da droga. Isto está de acordo com as considerações de Gava et al. (1997) que ressalvaram a diferença entre as quantidades ingeridas individualmente como função da dominância social de alguns animais, bem como a não aceitação da mistura por outros animais.

O curso clínico da enfermidade, que neste caso foi de três a cinco dias, depende da intensidade da dose e do tempo de ingestão do ionóforo (Rozza et al., 2007), sendo que em curso muito agudo, lesões macroscópicas não são observadas e, às vezes, lesões microscópicas estão ausentes. Além disso, morte súbita pode ocorrer alguns dias após a ingestão do produto provavelmente devido a alterações funcionais ou bioquímicas. Já em curso clínico mais longo, as lesões são mais pronunciadas e alterações reparativas podem ser vistas (Gava et al., 1997; Wouters et al., 1997). Somado a isso, é importante ressaltar a maior suscetibilidade dos ovinos comparados aos caprinos, uma vez que nenhum caprino da propriedade em questão apresentou sinais clínicos da intoxicação, apesar de terem recebido a mesma dieta.

As duas ovelhas foram tratadas com fluidoterapia intravenosa no primeiro dia de internamento, utilizando-se 1 litro de ringer com lactato. Após dois dias, por apresentarem melhora do quadro clínico, retornaram à propriedade. Em casos de intoxicação por ionóforos, não existe tratamento primário eficiente, sendo 
recomendado somente tratamento de suporte (Radostits et al., 2002). A solução cristalóide de ringer com lactato é a que apresenta composição mais próxima à do plasma. É empregada na maioria dos pacientes como fonte inicial e emergencial de reposição hidroeletrolítica (Dearo, 2002).

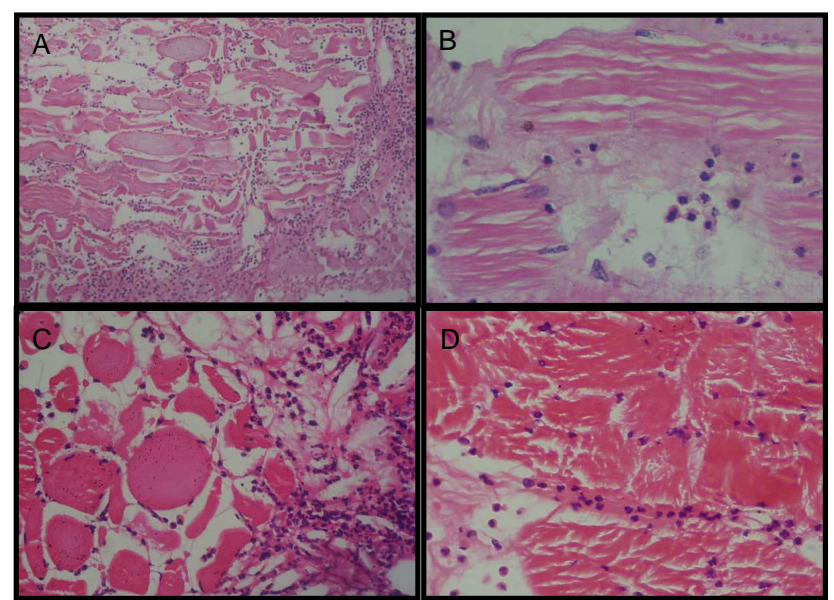

Figura 1. Ovino intoxicado por monensina. $[A$ e $B]$ Músculo esquelético apresentando perda de estriações longitudinais com hialinização do sarcoplasma e infiltrado inflamatório constituído predominantemente por polimorfonucleares, HE, obj. 10x, 40x respectivamente [C e D] Músculo cardíaco com necrose hialina segmentar multifocal associado a infiltrado inflamatório, HE, obj.40x.

$\mathrm{Na}$ necropsia do carneiro, constatouse que o mesmo possuía um bom estado nutricional, mucosas aparentes congestas, músculos esqueléticos em geral com coloração pálida e aspecto de cozido, principalmente no membro posterior direito, alças intestinais com serosas e mucosas hiperêmicas e conteúdo hemorrágico, caracterizando uma enterite hemorrágica, fígado aumentado de volume com congestão, edema pulmonar moderado, hidropericárdio, hemorragias no epicárdio, congestão dos vasos coronarianos e palidez do miocárdio.

O quadro anátomo-patológico não difere dos relatados por outros autores, sendo que os principais achados de animais intoxicados por ionóforos referem- se aos músculos esqueléticos e ao miocárdio, consistindo em áreas ou estrias branco-amareladas focalmente extensas ou difusas (Wouters et al., 1997; Gava et al., 1997; Bezerra Jr. et al., 2000; Mendes et al., 2003; Rozza et al., 2007).

Na microscopia (figura 1), utilizandose a coloração de hematoxilina-eosina, os músculos cardíaco e esquelético apresentaram fragmentação de feixes com hialinização do sarcoplasma, tumefação, ausência de estriações longitudinais e transversais e presença de picnose nuclear. Nos cortes transversais, foi possível observar perda da forma poligonal característica das miofibras que estavam arredondadas, tumefeitas e com marcada eosinofilia, caracterizando necrose hialina. Notou-se também que a fragmentação do sarcoplasma, por vezes, formava aglomerados de detritos eosinofílicos irregulares, descrevendo uma necrose flocular, concordando com as observações de outros autores em casos de intoxicação por ionóforos (Wouters et al., 1997; Gava et al., 1997; Bezerra Jr. et al., 2000; Mendes et al., 2003; Rozza et al., 2007). Além disso, foi observada infiltração inflamatória intersticial constituída predominantemente de polimorfonucleares, neutrófilos e eosinófilos, com alguns macrófagos, denotando a ocorrência de miocardite e miosite agudas. Entretanto, Wouters et al. (1997), Mendes et al. (2003) e Rozza et al. (2007) observaram infiltrados inflamatórios compostos predominantemente por macrófagos.

\section{CONCLUSÃO}

Baseando-se nas informações da anamnese, bem como nos sinais clínicos e nas alterações anátomo-histopatológicas, concluiu-se que os animais apresentaram um quadro de intoxicação pelo antibiótico ionóforo monensina. 


\section{REFERÊNCIAS}

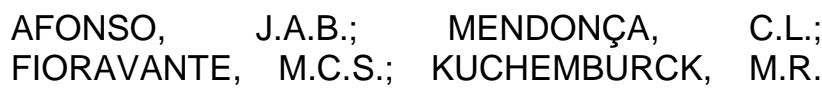
Características e indicações clínicas dos ionóforos para ruminantes. Revista CFMV, Brasília, v. 20, p.29-36, 2000.

BEZERRA JR, P.S.; ILHA, M.R.S.; LANGOHR, I.M.; BARROS, C.S.L. Intoxicação experimental por monensina em eqüinos. Pesquisa Veterinária Brasileira, Rio de Janeiro, v. 20, n.3, p.102-108, 2000.

DEARO, A.C.O. Fluidoterapia em animais de grande porte. In: ANDRADE, S.F. Manual de Terapêutica Veterinária. 2.ed. São Paulo: Roca, 2002, p. 486491.

GAVA, A.; WOUTERS, A.T.B.; WOUTERS, F.; NIZGOSKI, L.; BARROS, C.S.L. Intoxicação por salinomicina em bovinos. Pesquisa Veterinária Brasileira, Rio de Janeiro, v. 17, n.3/4, p.127-130, 1997.

GONZALES, M.; BARKEMA, H.W.; KEEFE, G. P. Monensin toxicosis in a dairy herd. The Canadian. Journal of Veterinary Research, Ontario, v.46, p.910-912, 2005.

MACHADO, G.V.; LESNAU, G.G.; BIRCK, A.J. Topografia do cone medular no lobo-marinho (Arctocephalus australis Zimmermann, 1803). Arquivos de Ciências Veterinárias e Zoologia da UNIPAR, Umuarama, PR, v.6, n.1, p.11-14, 2003.

MENDES, O.; MOHAMED, F.; GULL, T.; CONCHABERMEJILLO, A. Monensin poisoning in a sheep flock. Sheep \& Goat Research Journal, Aurora, v.18, p.109-113, 2003.

NATION, P.N.; CROWE, S.P.; HARRIES, W.N. Clinical Signs and Pathology of Accidental Monensin Poisoning in Sheep. The Canadian Journal of Veterinary Research, Ontario, v. 23, p.323-326, 1982.

NICODEMO, M.L.F. Uso de aditivos na dieta de bovinos de corte. Documentos 106, Embrapa Gado de Corte, Campo Grande-MS, p. 12-21, 2001.

OLIVEIRA, J.S.; ZANINE, A.M.; SANTOS, E.M. Uso de aditivos na nutrição de ruminantes. Revista Electrônica de Veterinária, Málaga, v.6, n.11, 2005.

RADOSTITS, O.M.; GAY, C.C.; BLOOD, D.C.; HINCHCLIFF, K.W. Intoxicação por ionóforos. In:

Clínica Veterinária - Um tratado de doenças dos bovinos, ovinos, suínos, caprinos e eqüinos. 9.ed., Rio de Janeiro: Guanabara Koogan, 2002, p.1466-1467.

ROZZA, D.B.; CORRÊA, A.M.R.; LEAL, J.S.; BANDARRA, P.M.; GUAGNINI, F.S.; RAYMUNDO, D.L.; DRIEMEIER, D. Intoxicação experimental por monensina em búfalos e bovinos. Pesquisa Veterinária Brasileira, Rio de Janeiro, v.27, n.4, p.172-178, 2007.

SANTIAGO, W. Esqueletopia do cone medular em Canis familiaris. Arquivo da Universidade Federal Rural do Rio de Janeiro, Seropédica, RJ, v.4, n.1, p.67-69, 1974.

SANTIAGO, W.; MACHADO, G.V.; VIZIOLI, V.P.; BARRA, P.H.M. Esqueletopia do cone medular em caprinos mestiços. CONGRESSO MINEIRO DE MEDICINA VETERINÁRIA, 9, 1990, Belo Horizonte. Anais, 1990. p.107.

SCHWARZE, E.; SCHRÖDER, L. Compendio de anatomía veterinária. Zaragoza: Acribia, 1972. p.26-27.

SEIFERLE, E. On the topography of the equine and bovine spinal cord. Zeitschrift für Anatomie, v.110, p.731-784, 1951.

VAN VLEET, J.F.; AMSTUTZ, H.E.; WEIRICH, W.E.; REBAR, A.H.; FERRNAS, V.J. Clinical, clinicopathological and pathological alterations in acute monensin toxicity in catle. American Journal of Veterinary Research, Schaumburg, v.44, n.11, p.2133-44, 1983.

WOUTERS, F.; WOUTERS, A.T.B.; BARROS, C.S.L. Intoxicação experimental por narasina em ovinos. Pesquisa Veterinária Brasileira, Rio de Janeiro, v.17, n.3/4, p.89-95, 1997. 